\title{
A Study of the Thermal Neutron Effects on the Optical Properties of CR-39 Solid State Nuclear Track Detector
}

\author{
Sheamaa T. Al-Dbag \\ Department of Biophysics \\ College of Science \\ University of Mosul
}

(Received 28/5/2013;Accepted 9/9/2013)

\begin{abstract}
This research involves studying the effect of thermal neutron on the optical properties of nuclear track detector (CR-39) exposed to radiation at different time ranges from (1 to 15) day at room temperature. The photo absorption was measured using a spectrometer (UV-1100). The results show that the coefficient of absorption increases by increasing time of neutron flux exposure. It was found that the energy gap values decrease with the increase of exposure radiation time, the results also show that the value of energy gap at direct effect (before and after) radiation is more than its value in the indirect effect, also the numbers of carbon atoms in a cluster were determined from UV-visible spectra of the thermal neutron irradiated samples.
\end{abstract}

Keywords: Neutron irradiation, optical band energy, CR-39 detector, UV-Visible spectroscopy, optical absorption.

\section{درلسة تألير النيترونلت الحرارية عل الخواص البصربة هلثف الأثر النووي الصلب}

\section{CR-39}

\section{الملغص}

يتضمن هذا البهث درلسة تأثير النيترونت الحرارية على الخصائص البصرية لكاثف الأثر النووي

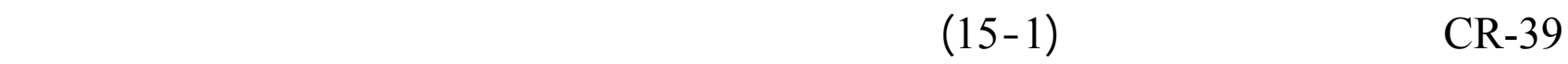

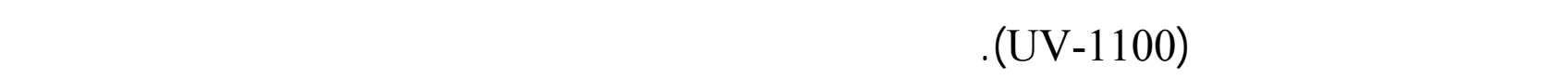

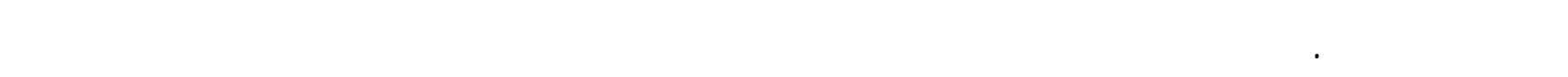

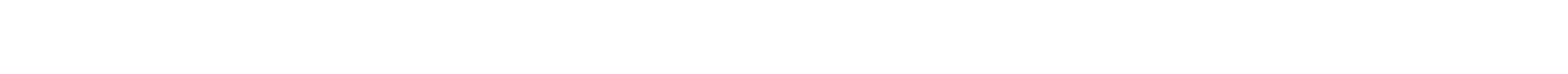

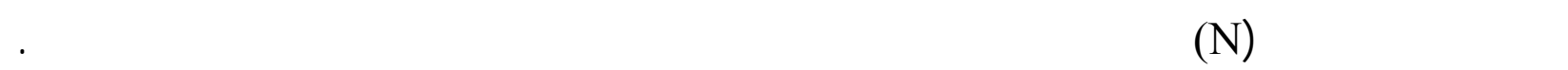

الكاملت الدالة: التعبع النيترون،طاقة الفجوة البصرية، كلثف الأثر النووي فوق البفسجية، الامتصاص البصري. 


\section{INTRODUCTION}

Polymers have proven potential in all fields during the last few decades. Different studies of the effect of irradiation on polymers, reveal a variety of the modifications of the physical and chemical properties such as optical, electrical, mechanical etc. of polymeric materials depending on the irradiation fleunce and the energy of the radiation used (Ramola et al., 2008). Interaction of radiation or highly energetic charged ion strikes a polymer target; it loses most of its energy in exciting or ionizing the atoms along its trajectory. Target ionization causes bond cleavage (scission), cross-linking, degradation, emission of atoms and molecules, creation of the free radicals and formation of saturated and unsaturated groups with stimulated evolution of gases. These modifications have strong influences on the optical properties of polymers. Most of the previous work has used electrons, protons, IR, X-rays and gamma rays irradiation etc (Zaki, 2008). A very few studies have been carried out on neuron induced effects, to modify its property to be suitable for radiation dosimetry applications. The neutrons themselves do not cause ionization directly, However the interesting part lies in the secondary effects due to neutrons which cause the proton recoil especially for $\mathrm{H}$ atoms (Kumar et al., 2010). The current study aims to study the effect of thermal neutron irradiation on the UV-visible spectra of CR-39 polymeric detector before and after irradiation, also study the effect of thermal neutron irradiation on the absorption coefficient and energy gap of the CR-39 polymer. Optical properties of the polymers have been characterized by various authors (Ramola et al., 2008) have tried to analyze the relation between radiation doses against band gap, (Zaki, 2008) by correlating the change in optical properties with the mode of energy deposition. We also investigate the number of carbon atoms in a cluster using Tauc's expression (Sharma et al., 2006).

\section{The theoretical part}

\section{Radiation effect on the polymers}

The effect of the radiation on polymers can either cause decay in which certain that lead to broken chemical bonds among atoms in polymer main chains resulting in polymer annealing loss or it is structural force and reduction in molecules weight (Billmeyer, 1965) or molecules overlap in polymers which are defined as reaction that can link polymerized chains with each other by crossed side bonds. That can result in complex overlapped structures enabling to increase polymer force, rigidity and molecular weight. Some physical changes that occur in polymers as a result of radiation can cause color or absorption change or lead to overlapped yield (Al-Nia'emi, 1998).

\section{Optical absorbance in the CR-39}

When passing radiation through a layer of transparent materials, the intensity of irradiance $\left(\mathrm{I}_{0}\right)$ in general is greater than the intensity of the transmitted radiation (I) because some of the photons of certain frequencies may be absorbed.

The intensity of the radiation absorbed is directly proportional to the number of molecules absorbing, this is the basis of Beer - Lambert law (Soulignac and Lamotte, 1987).

$$
I=I_{o} e^{-\alpha \tau}
$$

Where t: thickness of absorbent material, $\alpha$ absorption coefficient 


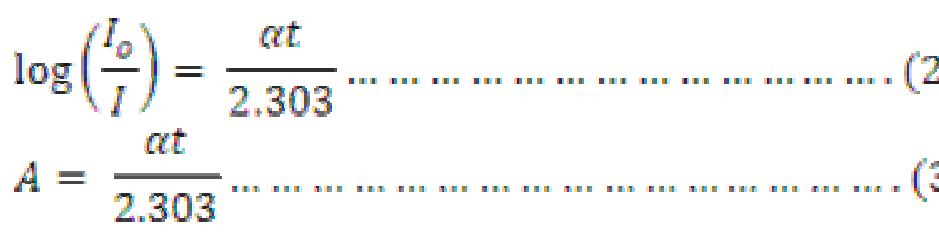

(A) know as $\log (\mathrm{Io} / \mathrm{I})$

$\alpha=\left(\frac{2.303}{t}\right) A$

The amount of radiation absorbed depends on the type and thickness of the absorbent material. The relationship between the energy gap $\left(E_{g}\right)$ and the absorption coefficient $(\alpha)$ and incident photon energy (hv) are given by the following relationship (Mott and Davies,1979).

$$
\alpha(h v)=B(h v-E g)^{n}
$$

where $h v$ is the energy of the incident photons, $E g$ is the value of the optical energy gap between the valence band and the conduction band, and $n$ is the power, which characterizes the electronic transition, whether it is direct or indirect during the absorption process in the K-space. Specially, $n$ is $1 / 2,3 / 2,2$ and 3 for direct allowed, direct forbidden, indirect allowed and indirect forbidden transitions, respectively. The factor $B$ depends on the transition probability and can be assumed to be constant within the optical frequency range. The usual method for the determination of the value of $E g$ involves plotting $(\alpha h v) 1=n$ against $(h v)$. Indirect transitions in many amorphous materials fit the case for $n=2$; for a direct transition a reasonable fit with $n=1 / 2$ is achieved. In the present study, the most satisfactory results were obtained by plotting $(\alpha h v) 1=2$ and $(\alpha h v) 2$ as a function of photon energy $(h v)$ respectively,

$E(\mathrm{eV})$ is the energy of incident photons and it can be calculated at the range (190$800 \mathrm{~nm}$ ), by the following relationship (Wong, 1998), (Patel, 2011).

$$
E(\mathrm{eV})=h v=\frac{1.241 \times 10^{-6}}{\lambda(\mathrm{nm})} \text {. }
$$

\section{EXPERIMENTAL PROCEDURE}

The present study was performed by using a commercially purchased CR-39 sheets with approximate thickness $250 \mu \mathrm{m}$ having density $1.3 \mathrm{~g} / \mathrm{cm}^{3}$ of size $1 \mathrm{~cm} \times 1 \mathrm{~cm}$. All the samples of CR-39 were irradiated at room temperature in (Dep. of Physics, College of Education Ibin Alheitheam University of Baghdad) by using Am-Be neutron source of $10^{5}$ $\mathrm{n} / \mathrm{cm}^{2}$ flux, time of irradiation is $(1,3,5,7,9,11,15)$ day. The samples were placed in polyethylene radiator of thickness $1 \mathrm{~mm}$. The irradiation facility is designed so that the neutron radiations are thermal using polyethylene as moderator. The pristine and neutron irradiated CR-39 polymeric samples was subjected to spectral studies in the ultraviolet and visible region performed to observe the variation in optical band gaps and the number of carbon atoms in a cluster using Tauc's expression. 


\section{RESULT AND DISCUSSION}

The optical absorption spectra of CR-39 irradiated by thermal neutron recorded using UV-visible spectrophotometer in the wavelength range (190-800) nm are shown in Fig. (1), indicating that the peak absorbance and area approximately increases with increasing irradiation time and decreases with the wavelength. Also the highest value for absorption increases with the increase of irradiation time. This behavior is generally interpreted as caused by the formation of extended systems of conjugate bonds i.e. possible formation of carbon clusters.

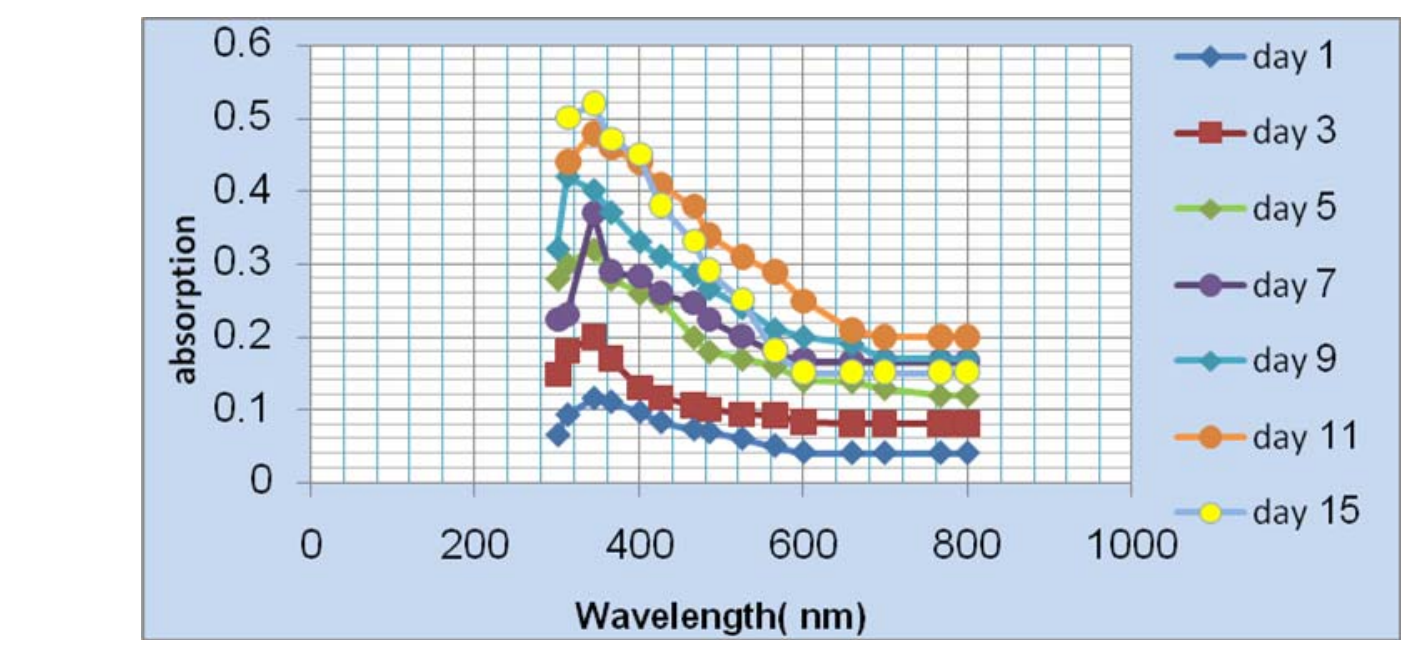

Fig. 1: UV-visible Spectra of thermal neutron -irradiated CR-39

Fig. (2) shows that the absorption coefficient is increasing with photon energy and increased with exposure irradiation time of thermal neutron flux, this agrees with (Sharma et al., 2006) and (Kumar et al., 2009).

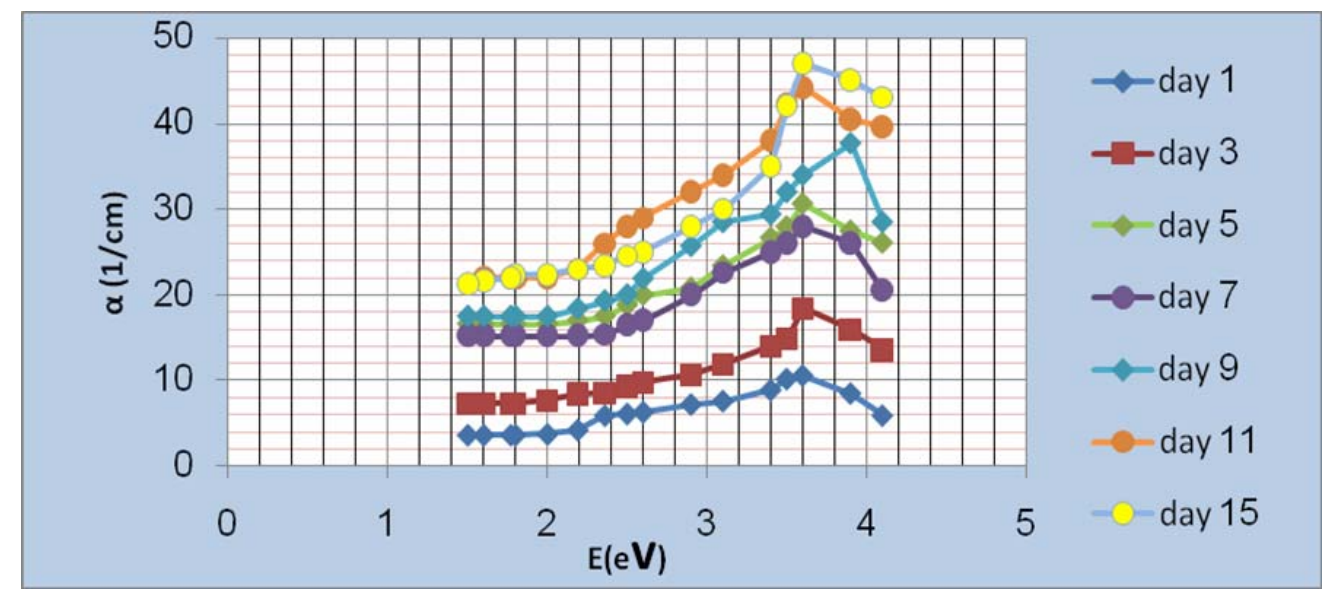

Fig. 2: The relationship between the absorption coefficient and incident photon energy for exposure irradiation time of thermal neutron flux.

Fig. (3) shows the relation between the absorption coefficient and the exposure irradiation time of thermal neutron. It is clear that the relation is represented by polynomial equation. Also the values of maximum absorption coefficient increase with increasing exposure irradiation time of thermal neutron, because of the radiation lead to break up the 
main equivalence bounds into radicals. This effect leads to increase the absorption of the incident radiation more than the absorption of the unradiated substance, and when the time of neutron irradiation increase these effects also increase, this leads to increase the absorption and this agrees with (Ashour et al., 2006).

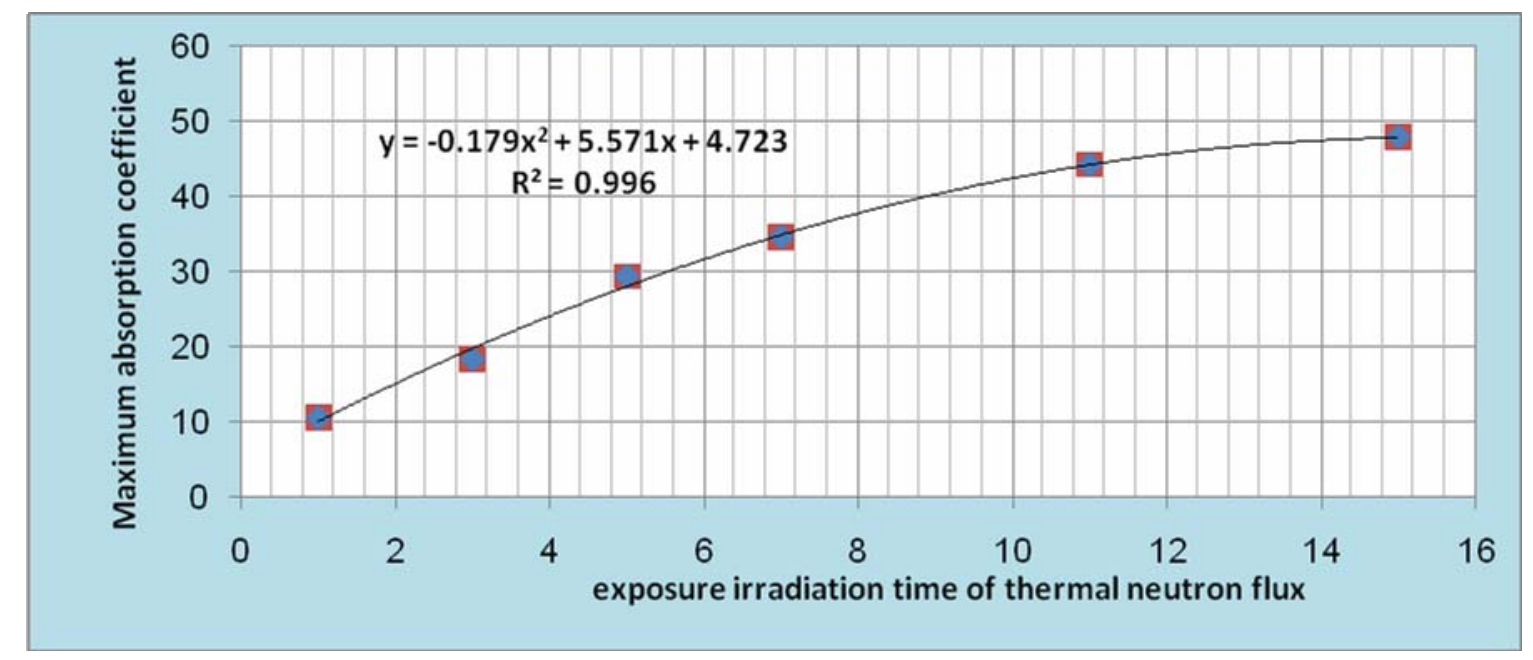

Fig. 3: The relationship between the maximum absorption coefficient and exposure irradiation time of thermal neutron flux

Figs. (4) and (5) show the values of the band gaps obtained by plotting $(\alpha E)^{2}$ and $(\alpha \mathrm{E})^{1 / 2}$ as a function of the photon energy $(\mathrm{E} \mathrm{eV})$, respectively and from the intersection of the tangent line with $\mathrm{x}$-axis. The optical band gap $\left(\mathrm{E}_{\mathrm{g}}\right)$ indirect and direct for pristine and neutron irradiated samples were determined and reported in (Table 1). It is concluded that the values of the direct and indirect are lower than the corresponding values of the direct and indirect band gap in pristine, and the value of energy gap in the case of indirect transitions, in all case are lower than the energy gap of direct transition, due to the presence of delocalized state between valance and conduction band. (Kumar et al., 2009) found similar behavior with Neutron Induced Modification on optical band gap of CR-39 Polymeric Detector, also (Zaki, 2008) found a similar pattern with gamma induced modification on optical band gap of CR-39. 

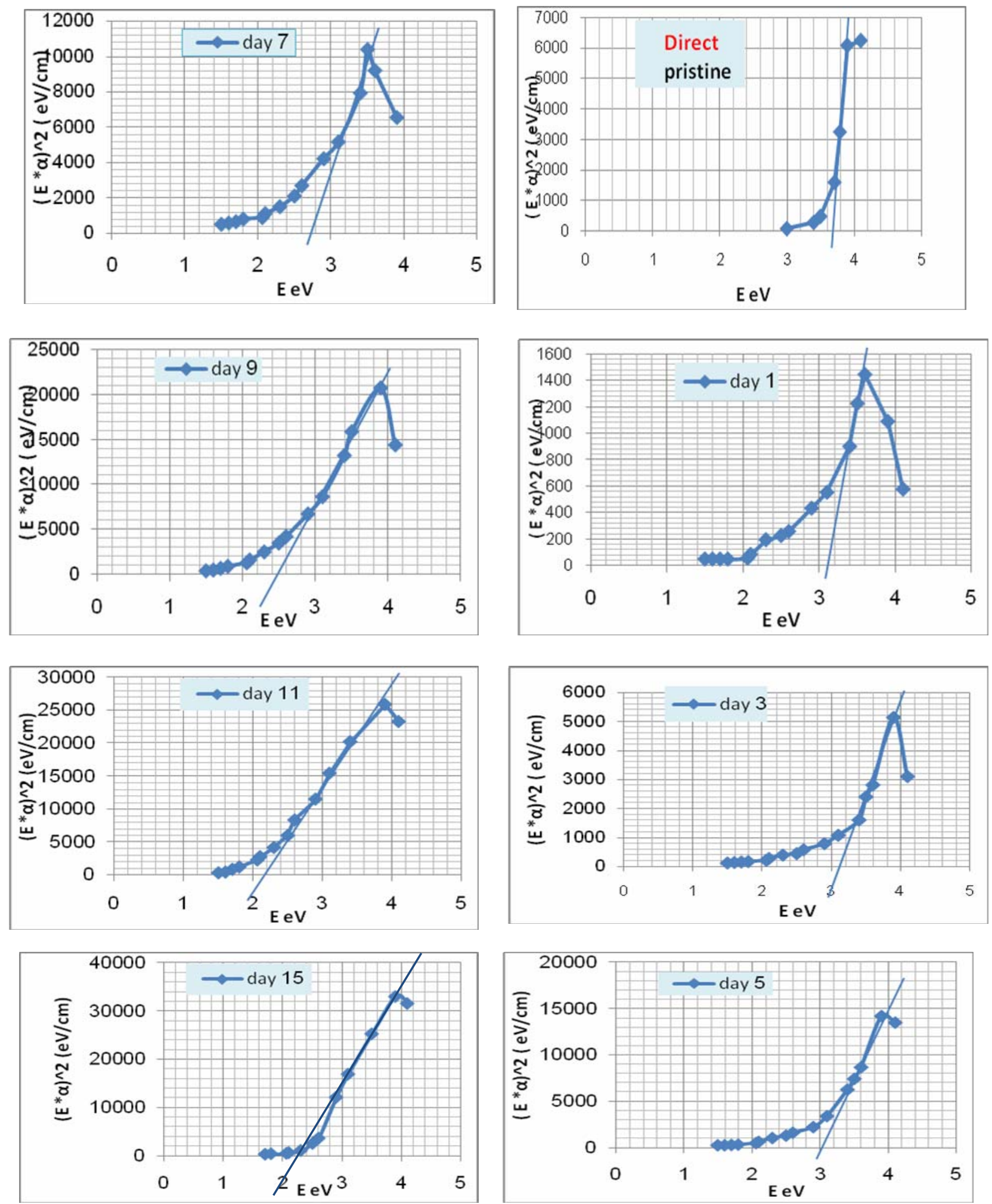

Fig. 4: The relationship between $\left(E^{*} \alpha\right)^{2}$ and the incident photon energy for pristine (not irradiated) and for different exposure time (day). 

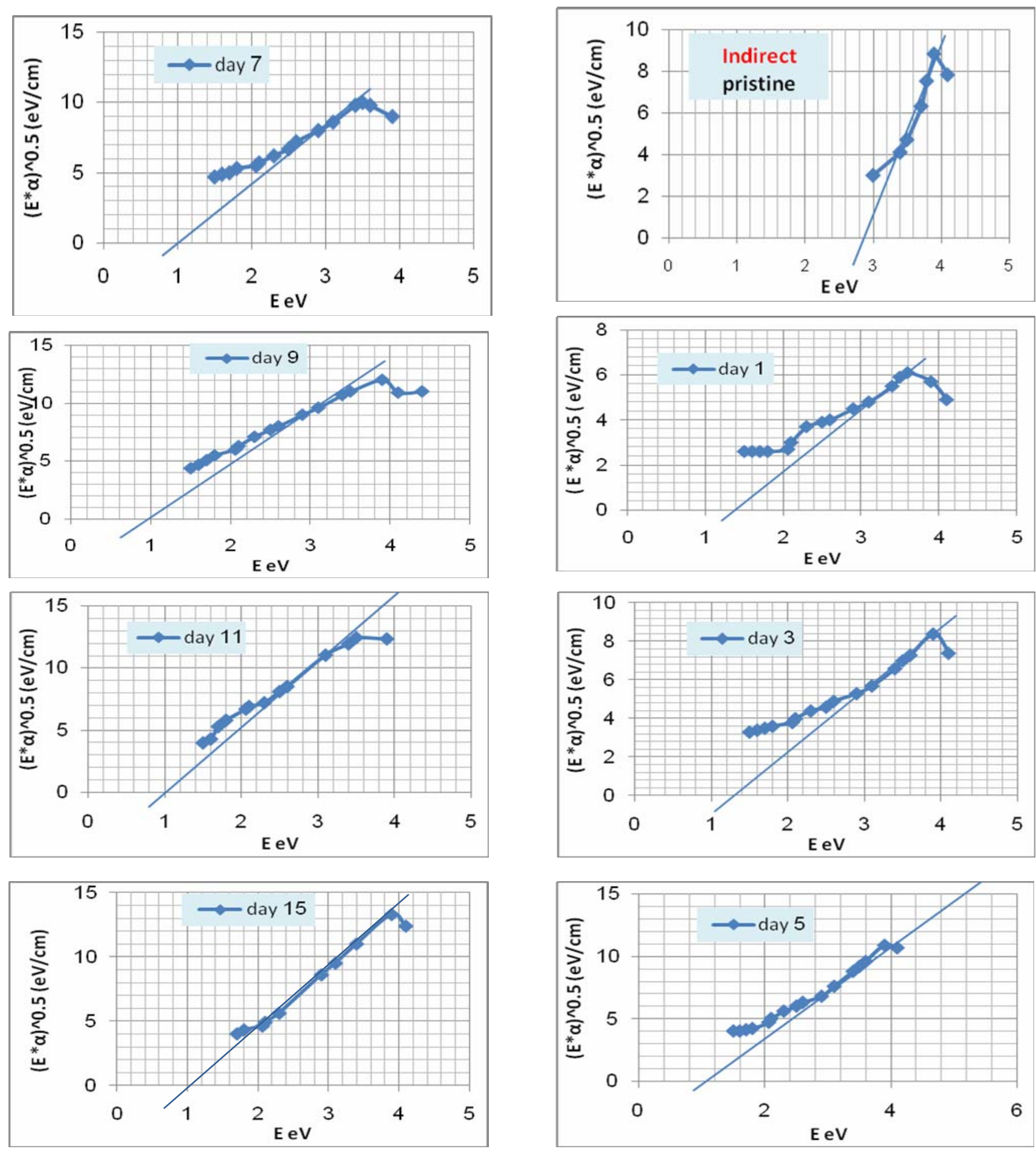

Fig. 5: The relationship between $\left(E^{*} \alpha\right)^{1 / 2}$ and the incident photon energy for pristine (not irradiated) and for different exposure time (day). 
Fig. (6) shows the relation between the band gap energy and the exposure irradiation time of thermal neutron flux. It is clear that the relation is represented by polynomial equation. Also the values of energy gap $\left(\mathrm{E}_{\mathrm{g}}\right)$ decrease with the increase of exposure time. This decrease in $\mathrm{E}_{\mathrm{g}}$ values may be due to the degradation of CR-39 and the formation of defects and cluster in the material, while the cluster size increases with the increase in the fluency for both cases. This agrees with (Kumar et al., 2009) and (Holbert, 1995).

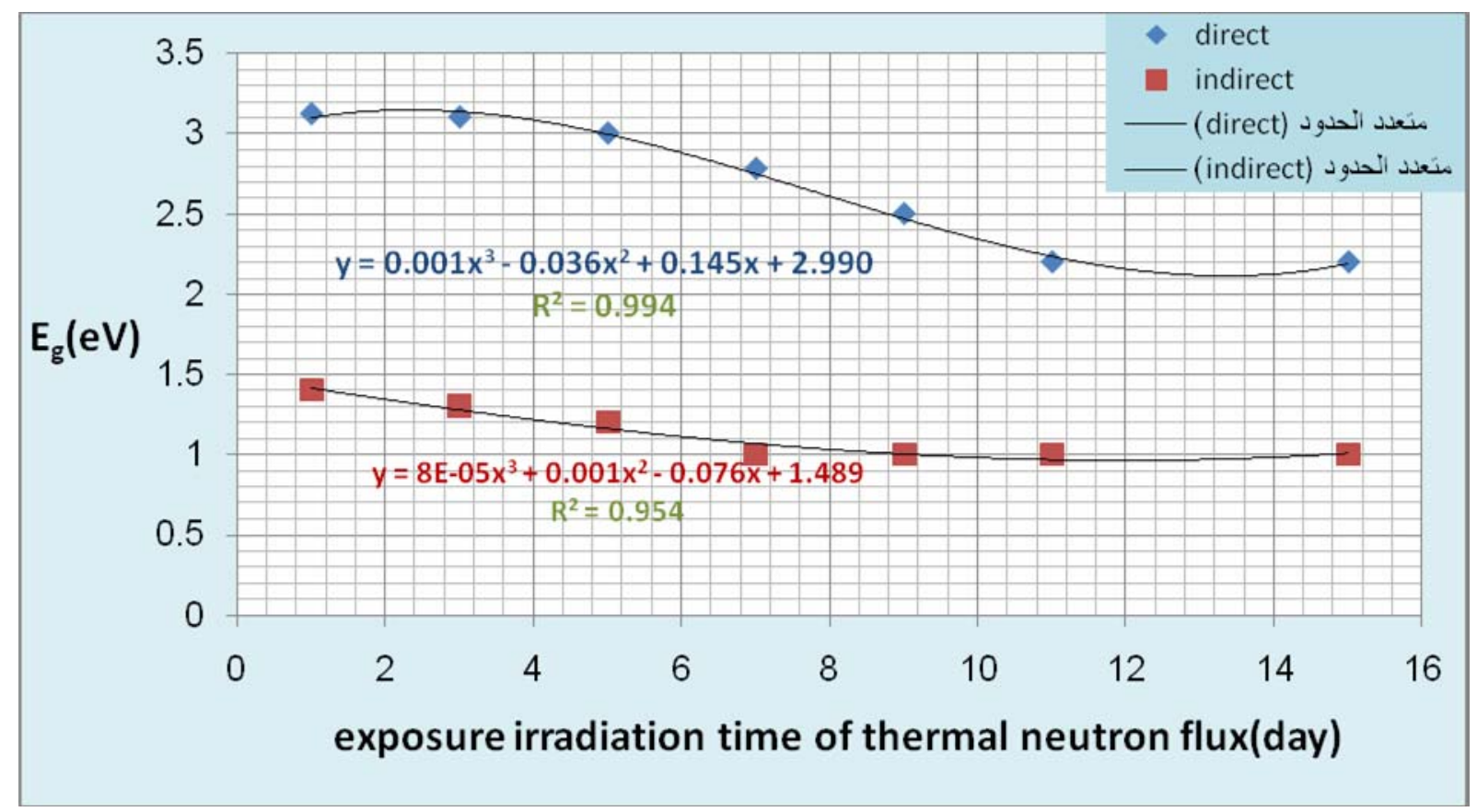

Fig. 6 : The relationship between band gap energy (eV) and exposure irradiation time of thermal neutron flux.

For a linear structure, the number of carbon atoms $(\mathrm{N})$ in the cluster per conjugation length is given by the following relation (Zaki, 2008).

$$
\mathrm{N}=2 \beta \pi / \mathrm{E}_{\mathrm{g}}
$$

Here $2 \beta$ gives the band structure energy of a pair of adjacent $\pi$ sites. The value of $\beta$ is taken to be $\approx(2.9 \mathrm{eV})$. As it is associated with $\left(\pi-\pi^{*}\right)$ optical transition in $(-\mathrm{C}=\mathrm{C}-)$ structure.

Table 1: The variation of the band gap energy in the pristine and neutron irradiated CR-39, along with the number of carbon atoms (N)

\begin{tabular}{|c|c|c|c|c|}
\hline \multirow{2}{*}{$\begin{array}{c}\text { Exposure } \\
\text { Time (day) }\end{array}$} & \multicolumn{2}{|c|}{ Band gap energy ( $\mathrm{eV})$} & \multicolumn{2}{c|}{ No. of carbon atoms (N) } \\
\cline { 2 - 5 } & Indirect & Direct & Indirect & Direct \\
\hline Pristine & 2.9 & 3.7 & 6 & 5 \\
\hline 1 & 1.4 & 3.12 & 13 & 6 \\
\hline 3 & 1.3 & 3.1 & 14 & 6 \\
\hline 5 & 1.2 & 3 & 15 & 6 \\
\hline 7 & 1 & 2.78 & 18 & 7 \\
\hline 9 & 1 & 2.5 & 18 & 7 \\
\hline 11 & 1 & 2.2 & 18 & 8 \\
\hline 15 & 1 & 2.2 & 18 & \\
\hline
\end{tabular}




\section{CONCLUSIONS}

- The values of indirect band gap are lower than the corresponding values of direct band gap in pristine and neutron irradiated CR-39, also the band gap $\left(\mathrm{E}_{\mathrm{g}}\right)$ decrease with the increase of exposure irradiation time of thermal neutron flux for both cases, due to the degradation of CR-39 and the formation of defects and cluster in material, while the cluster size increase with the increase in the flux for both cases.

- The highest value for absorption increases with the increasing time of irradiation.

- Absorption coefficient of CR-39 increases with increasing time of irradiation.

- The atomic number $(\mathrm{N})$ for $\mathrm{CR}-39$ increase with increasing exposure irradiation time of thermal neutron flux.

\section{REFERENCES}

Al-Niaemi, S.H. (1998). Effect of electromagnetic radiation on the properties of nuclear track detector CR-39 and building of electrochemical etching system. Ph.D., Thesis, University of Mosul, Iraq.

Ashour, A.H.; Saad, H.M.; Ibrahim, M.M. (2006). Electrical conductivity for irradiated grafted polyethylene with metal complex . Egypt. J. Solid, 29(2), 315-360

Billmer, F.W. (1965). "Text Book of Polymer Science". John Wiley and Sons. Inc. U.S.A.

Holbert, K.E. (1995). Radiation effect and damage from http://nolbert Faculty. asu. edu/Radiation effect Damage. pdf.

Kumar, V.; Sonkawade, R.G.; Dhaliwal, A.S.; Mehra, R. (2009). Study of neutron induced modification on optical band gap of CR-39 polymeric detector. Asian J. Chem., 21(10), 279-283.

Kumar, V; Sonkawade, R.G.; Dhaliwal, A.S. (2010). Optimization of CR-39 as neutron dosimeter. Indian J. Pure and Applied Physics, 48, 466-469.

Mott, N.F.; Davies, E.A. (1979). "Electronic Processes in Non-Crystalline Materials". Clarendon press, Oxford.

Patel, S.B. (2011). "Nuclear Physics: An Introduction". 2nd ed., Amazon.

Ramola, R.C.; Chandra, S.; Negi, A.; Rana, J.M.S.; Annapoorinal, S.; Sonkawade, R.G.; Kulrlya, P.K. (2008). Study of optical band gap, carbonaceous clusters and structuring in CR-39 and PET polymers irradiated by $100 \mathrm{MeV}$ O7+ ions. Physics B: condensed matter. 404, 26-30.

Sharma, G.; Thind, K.S.; Manupriya; Klare, H.S.; Narang, S.B.; Gerwardli; Dangwall, V.K.; (2006). effect of Gamma-ray irradiation on optical properties of Zon-Pho$\mathrm{B} 2 \mathrm{O} 3$ glasses. Nuclear instrument and methods in physics research section $B$. Beam Interaction with materials and atoms, 243, 345.

Soulingac, J.C.; Lamotte, M. (1987). AUV-Vis spectrophotometer for absorbance measurements of weakly trans parent light scattering samples. Applied Spectroscopy, 41, 1101-1261.

Wong, S.M. (1998). "Introductory Nuclear Physics". 2nd ed., John Wiley and Sons, USA.

Zaki, M.F. (2008). Gamma induced modification on optical band gap of CR-39 SSNTD. Phys. D : Appl. Phys., 38(4), 558-562. 